\title{
Religious Minorities and the Graduate School Experience
}

Sierra Davis Thomander; sierrad@stanford.edu

Andrea Malji; amalji@hpu.edu

This chapter examines the challenges facing graduate students who are religious minorities, defined broadly. Specifically, it examines some of the prevailing concerns including dietary accommodations, socialization habits, cultural differences, and holiday/calendar differences. In particular, the normalization of Christian holidays and calendars, even in supposedly secular settings, has the potential to be exclusionary. Even within Christianity, there are minority religions that differ in practices, beliefs, worship dates, and holidays. Within the field of political science specifically, students may also have to navigate feeling called to be a representative or defendant of their religion, especially if others within the department are studying the political dynamics of their religion. Like other minorities, religious minorities may face discrimination, microagressions, and unwelcome questioning or criticisms about their faith practices as well as outright harassment and assault. Students should be empowered to advocate for their rights and respectful treatment. Graduate school may also have certain socialization norms that are counter to the beliefs of certain religions, such as centering socialization around alcohol or assuming certain dates are free for scheduling.

We provide several recommendations for graduate students about using university resources, establishing boundaries and healthy dialogue, and proactively advocating for your religious needs. We also discuss the trade-offs of concealing or disclosing different aspects of one's religious identity in different contexts. We conclude with best practices for graduate students, both religious and non-religious, that will foster inclusion and respect among people of different beliefs, and additional resources.

\section{Why Does It Matter?}

Academia thrives when people from different backgrounds respectfully come together to learn, grow, and produce knowledge. Though individuals' religious backgrounds can and do inform their contributions in advancing scientific understanding, these backgrounds should not hinder opportunities and resources nor pose obstacles to completing a graduate degree. While civil rights laws have formally instituted these ideals in general, in practice discrimination occurs frequently. In one study, people who practice Judaism, Islam, and to a lesser extent Christianity report facing religious hostility, discrimination, and at times violence in their pursuit of scientific knowledge, as do other religious minorities such as Sikhs (Scheitle and Ecklund 2020). Even those lacking a religion can face discrimination (Scheitle and Ecklund 2020, 141). Even among Christians, discrimination occurs due to creed, denomination, and practices (Scheitle and 
Ecklund 2020; Rosentiel et al. 2007). Status as a religious minority may depend on the specific institutional and cultural context rather than population-based understanding of minority status. For instance, though the United States has more Catholics than Latter-day Saints, a Catholic attending the Latter-day Saints-affiliated Brigham Young University would effectively be a religious minority. Addressing this discrimination, both as individuals who navigate it and allies seeking to help, is critical to fostering an inclusive environment.

Addressing these concerns for graduate students is particularly important for both individual graduate school experience as well as the future of the discipline and its output. Graduate students deserve a respectful, open environment in which to learn, grow, and collaborate. Students at all levels benefit from the diversity that these environments create as well-supported graduate students become faculty. Admission of a diverse candidate pool is superfluous if the pipeline "leaks" such promising scholars due to religious discrimination and hostility.

Religious minorities in political science may also encounter a unique challenge related to the disciplinary study and analysis of religion. Unlike some fields, social sciences are inextricably linked to discussion of religion. From modern-day voting behavior to medieval state formation, religion often plays an important role in political science. While some scholars study questions that relate to their background, others do not. The intersection of backgrounds, beliefs, and research in addition to religious content can produce difficult environments. Students may find that scholars who study their religion seem distant or overly critical. This may make the student feel uncomfortable within the classroom, particularly when their religion is examined critically.

For example, Islam has increasingly been analyzed within the context of terrorism and extremism. A Muslim in a class reading articles about these topics, or engaging with classmates or faculty that study it, may feel their religion is being unnecessarily reduced to an analytical category. Likewise, Hindus, Sikhs, or Buddhists may feel similarly when religious nationalism in South Asia is discussed. This student may also feel marginalized or called to defend their religion from critique. At some institutions, people tend to assume that academics are secular/non-religious. This could potentially lead to microaggressions or unwelcoming questions by non-religious persons regarding your spiritual choices. Because the best research often benefits from diverse perspectives and expertise, the political science discipline benefits when we focus on addressing these issues to create better environments while still exploring questions where religion and science intersect.

\section{What Should/Can You Do?}

The issues religious minorities face may range in severity. From insensitive comments to outright violence, these challenges can not only make an already difficult time even worse but may even impede progress and degree attainment. Strategies for dealing with these challenges 
depend on the severity of the challenge, the context, and the resources available. While graduate students can preempt some issues or easily solve others, some may take more formal pathways and resources. While we suggest first beginning with more informal and preventative approaches, graduate students should not hesitate to escalate concerns as needed. We discuss strategies in the following sections.

\section{Disclosing Your Religion}

Your religious affiliation and beliefs are personal matters. How public you make them is up to you. However, disclosing your affiliation/belief is often necessary to receive accommodations, explain your background and research interests, and engage in other opportunities. Universities often ask incoming students and applicants to indicate their religious affiliation, though you may opt to not disclose this information. Many graduate students fear disclosing their religion will result in discrimination and harassment. Your comfort level may also depend on your environment and affiliation. For instance, while you may feel apprehensive about disclosing your religious information when deciding between graduate schools, the feedback you receive by doing so can be highly useful in finding the right "fit." You may wish to use reactions to your religious information as a signal of each program's willingness to provide a positive environment and support for your unique circumstances. You may also need to disclose religious information to receive accommodations for religious holidays and worship. Talking with other religious minority students about their experience, if possible, is useful even if they do not share the exact same religion. It is also reasonable to disclose basic details about your religion while declining to discuss or disclose more specific details. You can exercise this right by simply saying, "I appreciate your curiosity, but I would rather not discuss that right now," in response to uncomfortable questions. Only you will know the right balance when it comes to disclosure.

\section{Be Aware of Your Institution's Resources and Limitations}

Specific characteristics of institutions often determine which resources, legal and otherwise, graduate students can use when facing challenges as a religious minority. Whether the educational institution is public or private is critical in understanding which laws, agencies, and resources are at graduate students' disposal. Prospective graduate students may wish to take public vs. private status, as well as other factors such as religious affiliation, into consideration when applying for and deciding between graduate programs (see "Selecting a Program" chapter).

A variety of agencies and departments within the United States cover religious discrimination, though often through different laws. Though none of the following information constitutes legal advice, the following agencies and resources can provide more information for individual graduate students. While the U.S. Department of Education's Office for Civil Rights (OCR) enforces civil rights laws that protect against discrimination on the basis of race, color, national 
origin, sex, disability, and age, none of the laws OCR enforces explicitly covers religious discrimination. However, Title VI of the Civil Rights Act of 1964 (Title VI) protects students of any religion from discrimination, including harassment, based on a student's actual or perceived 1) shared ancestry or ethnic characteristics, or 2) citizenship or residency in a country with a dominant religion or distinct religious identity (OCR 2020). The U.S. Equal Employment

Opportunity Commission (EEOC) covers employment discrimination based on religion, including harassment that creates a hostile or offensive work environment of adverse employment decision, which may or may not apply to graduate students (EEOC 2021). For oncampus housing, see the U.S. Department of Housing and Urban Development's Office of Fair Housing and Equal Opportunity website (FHEO 2021). The U.S. Department of Justice's Civil Rights Division also protects against some forms of religious discrimination in public school settings (U.S. DOJ CRD 2015). Individual states may have additional bureaucratic and legal resources. See the Helpful Websites and Resources section at the end of this chapter.

While federal and state resources are useful, they often lack coverage of all issues and circumstances, particularly for attendees at private institutions. However, many individual institutions, regardless of public/private status, have their own resources and rules available to assist religious adherents in both practicing their faith and navigating challenges. While most academic institutions will cite civil rights requirements on their websites, some have additionally established offices for religious life, diversity, and inclusion offices and programs, and representatives in administration and student government. For instance, Stanford University has both a Diversity and Access Office and Office for Religious and Spiritual Life as well as Student Associated Religions (SAR) Groups, which provide resources and support to students seeking religious accommodation or facing discrimination (Stanford Earth 2021). You will need to explore which offices deal with religious issues at your educational institution. The extent to which these offices assist students with grievances differs by institution. If possible, discuss with current students before deciding on a graduate program (see "Selecting a Program" chapter).

\section{Addressing Diet, Schedule, and Socialization Issues}

Religious minorities may encounter several challenges within their department and their university more broadly. Being aware of these challenges and devising strategies to address them early is critical. For instance, even in secular institutions, the academic calendar centers around Christian holidays. Meanwhile, universities rarely take the significant holidays for other religions into consideration. Universities and professors may not only expect religious minorities to attend class during their significant holidays but may also schedule important deadlines or exams during these times. Non-Christian students may also feel obligated to attend department holidaythemed celebrations which privilege, whether explicitly or implicitly, Christian holiday traditions. Furthermore, these events usually center around food which may pose additional challenges for students with religious dietary restrictions. Additionally, food-based social events 
may coincide with a period of fasting (e.g., Ramadan, Yom Kippur, Shivratri, etc.) or exclude people who abstain from certain food, drink, or preparation methods (e.g., alcohol, coffee, nonhalal foods, non-kosher foods, non-vegetarian options). Others may also question or even mock the wisdom or necessity of religious lifestyle choices, such as covering one's hair, abstaining from alcohol, or marrying young. While such circumstances often arise out of ignorance, they nevertheless negatively affect graduate students in their ability to socialize, network, etc.

While each individual will have different levels of comfort disclosing religious information, students will likely find it necessary to advocate for themselves to receive accommodations. This is especially true with calendar changes. Contacting advisors and professors at the beginning of the semester to inform them of any scheduling conflicts, such as exams on religious holidays, is crucial. The same is true for any dietary restrictions at department and student events. You may find that providing suggestions for alternative food and beverage options can be helpful. The increase of vegetarian and vegan options for non-religious reasons may provide an easy option when certain meat and animal products are restricted. Do not hesitate to collectively address dietary accommodations with other students, even if their dietary restrictions and reasoning differ. Your university's Office of Inclusion and Diversity or Office for Religious Life may also have resources and advice when navigating these accommodations. The main takeaway is to be proactive; address your concerns early and with additional support if desired.

Graduate school can be an isolating experience. Recent studies demonstrate that as many as $15.8 \%$ of graduate students experienced suicidal tendencies in the previous two weeks, $30 \%$ met the criteria for depression, and $32 \%$ met the criteria for anxiety (Almasri, Read, and Vandeweerdt 2021). Inclusion is no substitute for adequate mental health resources and institutional support (see chapters in the Mental Health and Wellness in Graduate School section). However, building an inclusive and safe graduate community may help dampen feelings of isolation that are common in graduate school. Graduate student social activity boards/committees help plan activities that allow students to feel engaged within the community. However, such social activities often center around alcohol and late night settings. This may cause feelings of discomfort and judgment for those abstaining from alcohol and related settings. By volunteering for the social activities board, religious minorities can help provide more inclusive alternatives. Additionally, many individuals choose not to consume alcohol for nonreligious reasons and may also feel uncomfortable in settings that include social pressure to drink. In fact, an increasing number of graduate students report substance abuse. Therefore, there are social benefits beyond the inclusion of religious minority perspectives. Having social activities that include religious minorities will help challenge the existing social activities paradigm. Consider serving on or offering to advise people on social activity committees/boards. Your contribution will not only benefit your own experience but also other religious minorities and future students. 
Negative Interactions: From Difficult Conversations and Microaggressions to Harassment and Assault

Negative interactions, whether in the classroom, with an advisor, or with a fellow student, can cause harm mentally, socially, and even physically. As with many negative interactions, the reaction and response to such harmful discriminatory behavior depends on the extent of harm itself. For instance, microaggressions (commonplace slights, intentional or not, that communicate hostile, derogatory, or negative attitudes toward marginalized groups) may not require formal institutional action whereas assault and harassment should always involve university action (Sue 2010). While you should report harassment and assault immediately, other negative interactions that fall short of harassment are nevertheless harmful. For instance, fellow graduate students in a comparative politics seminar may continually label a Buddhist student's interest in fellow Buddhists' voting behavior as "too niche," or a professor may make jokes about religious clothing at the expense of a Muslim student in class. These examples and others, while individually falling short of the definition of harassment, nevertheless harm students in their ability to academically succeed, especially when occurring frequently. While any individual action may feel dismissible, the accumulation of these negative experiences is not.

There are a few approaches to dealing with microaggressions in academic settings. You should read through the following and may research further to decide which approach works best for you. Ronald A. Berk has created a trilogy of articles on microaggressions and approaches to dealing with them (2017a; 2017b, 2017c), which may apply well to microaggressions directed at religious minorities. While victims of microaggressions are understandably reluctant to address the situation, especially when feeling ambiguous as to whether a microaggression occurred or when the interaction catches you "off guard" (Berk 2017b, 75). However, failure to respond may inadvertently condone the microaggression. If unable to address the issue in the moment, a delayed response is better than none and may even allow you to gather your thoughts and provide the environment for a better response. The goal of your response, Berk argues, "should be correction and education, not retribution," with a focus on words and behavior rather than the actual person $(2017 \mathrm{~b}, 75-6)$.

The five generic strategies are 1) say something on the spot, so the aggressor knows about the harm caused, 2) address the aggressor privately after the incident has occurred, 3) offer to help and create an ongoing dialogue to educate the aggressor, 4) change the subject, and 5) engage in proactive "microresistance." Microresistance involves four steps (Ganote et al. 2016; Irey 2013; Rockquemore 2016). First, observe by stating in clear, unambiguous language what you see happening. Second, express what you think or what you imagine others might be thinking. Third, express your feelings about the situation. Finally, state what you would like to have happened (desire) (Berk 2017b, 76). These approaches can foster honest communication, help others understand and validate your perspective, establish healthy boundaries, and avoid future 
microaggressions against yourself and others (77). The R.A.V.E.N. process (redirecting the conversation or interaction, asking probing questions, values clarification, emphasizing your own thoughts, and offering concrete next steps) is a similar approach that you may find useful (Harris and Wood 2020). Approaching trusted colleagues as allies can also help in navigating negative interactions. Repeated incidents may require more formal assistance. Any harassment or assault should always be formally reported. See chapters in the Climate and Culture in the Department and Profession section, especially "Implicit Bias and Microaggressions," "Discrimination and Assault", and "Harassment," for more information.

Subject matter and discussions in political science may also pose challenges. Discussing something personal and sacred in a critical, academic context is often challenging even when others are being respectful. While you should address microaggressions and discrimination, it can be helpful to reframe these discussions and subject matter as opportunities to learn from other perspectives, to educate others through your perspective, and to deepen your own understanding of faith and scholarship. You may benefit from supportive groups with members of your own faith, religious leaders, and even licensed counselors/therapists. Maintaining the balance between critical analysis/discussion expected in academia with the need for respect is often difficult. One helpful tip is to frame contributions as your perspective rather than universal truth and encourage the same in others. Approach these topics with humility while encouraging the same in others, but also set boundaries that maintain respect. While you may not always receive respect, you signaled that you do not silently tolerate such behavior but are open to discussion and learning.

\section{Conclusion}

Religious minorities must be aware of the unique challenges they may face and be prepared to advocate for themselves in several capacities. It is also critical to note that students may face intersecting challenges related to their gender, race and ethnicity, sexuality, disability, etc. See other chapters in the Strategies for Addressing Implicit Bias, Harassment, Assault section such as "Concerns for Individuals from Underrepresented Racial and Ethnic Minority Groups," "Concerns for LGBTQIA+ Individuals," and "Concerns for Women" for more information. Strategies offered here are merely an overview and each student will have individualized circumstances. Each student should investigate their specific program in detail to understand what resources they have available to help advocate for themselves. Being proactive for both yourself and fellow religious minorities will help mitigate major challenges and promote success.

\section{Helpful Websites and Resources}

U.S. Department of Education's Office of Civil Rights Website

U.S. Equal Employment Opportunity Commission Religious Discrimination Webpage

U.S. Department of Justice Civil Rights Division: Discrimination Webpage

U.S. Office of Fair Housing and Equal Opportunity Religious Discrimination Webpage 
How to be an Ally for Those Experiencing Microaggressions

Ronald A. Berk's Publications on Microaggressions

Harris and Wood's R.A.V.E.N. Process for Responding to Microaggressions 


\section{References}

Almasri, Nasir., Blair Read, and Clara Vandeweerdt, C. 2021. Mental Health and the PhD: Insights and Implications for Political Science. PS: Political Science \& Politics, 1-7. doi:10.1017/S1049096521001396

Berk, Ronald A. 2017a. "MICROAGGRESSIONS TRILOGY: Part 3. Microaggressions in the classroom." Journal of Faculty Development 31, no. 3: 95-110.

Berk, Ronald A. 2017b. "MICROAGGRESSIONS TRILOGY: Part 2. Microaggressions in the academic workplace." Journal of Faculty Development 31, no. 2: 69-83.

Berk, Ronald A. 2017c. "MICROAGGRESSIONS TRILOGY: Part 1. Why do microaggressions matter?" Journal of Faculty Development 31, no. 1: 63-73.

Ganote, Cynthia, Floyd Cheung, and Tasha Souza. 2016. "Micro-aggressions, micro-resistance, and ally development in the academy." Invited workshop presented at the National Center for Faculty Development and Diversity, Detroit, MI, April 7. http://www.faculty diversity.org/page/MicroAggressions/?src=IHEArticle

Harris III, Frank, and J. Luke Wood. 2020. "How to Respond to Racial Microaggressions When They Occur." Diverse: Issues in Higher Education Opinion Piece, May 5. Last updated May 6, 2020. https://www.diverseeducation.com/opinion/article/15106837/how-to-respo nd-to-racial-microaggressions-when-they-occur.

Irey, Sayumi. 2013. "How Asian American women perceive and move toward leadership roles in community colleges: A study of insider counter narratives." Unpublished doctoral dissertation, University of Washington. https://digital.lib.washington.edu/researchwo rks/bitstream/handle/1773/22898/Irey_washington_0250E_11343.pdf?sequence=1.

Office for Civil Rights. 2020. "Protecting Students: Religious Discrimination." U.S. Department of Education, December 4. Accessed November 27, 2021. https://www2.ed.gov/about/offices/list/ocr/religion.html.

Rockquemore, Kerry Ann. 2016. April 13). "Allies and Microaggressions." Inside Higher Ed, April 13. Accessed December 12, 2021. https://www.insidehighered.com/advice /2016/04/13/how-be-ally-someone-experiencing-microaggressions-essay. 
Rosentiel, Tom, Scott Keeter, and Gregory Smith. 2007. "Public Opinion About Mormons: Mitt Romney Discusses His Religion." Pew Research Center, December 4. Accessed November 24, 2021. https://www.pewresearch.org/2007/12/04/public-opinion-about-mor mons/.

Scheitle, Christopher P., and Elaine Howard Ecklund. 2020. “Individuals' Experiences with Religious Hostility, Discrimination, and Violence: Findings from a New National Survey." Socius: Sociological Research for a Dynamic World 6 (January): 1 -15. https://doi.org/10.1177/2378023120967815.

Sue, Derald Wing. 2010. Microaggressions in Everyday Life: Race, Gender, and Sexual Orientation. John Wiley \& Sons: Hoboken, New Jersey.

U.S. Equal Employment Opportunity Commission. 2021. "Religious Discrimination." EEOC Employees \& Job Applicants: Discrimination by Type, January 15. Accessed November 27, 2021. https://www.eeoc.gov/religious-discrimination.

U.S. Department of Housing and Urban Development's Office of Fair Housing and Equal Opportunity. 2021. "Religious Discrimination." Accessed November 27, 2021. https://portalapps.hud.gov/AdaptivePages/HUD/about/index.htm\#religion.

U.S. Department of Justice Civil Rights Division. 2015. "Educational Opportunities Section If You Have Been Discriminated Against." U.S. Department of Justice Home: Civil Rights Division, August 6. Accessed November 27, 2021.https://www.justice.gov/crt/educationa 1-opportunities-section-if-you-have-been-discriminated-against. 